\title{
Transport indicator analysis and comparison of 151 urban areas, based on open source data
}

\author{
Ali Enes Dingil ${ }^{1 *}$ (D, Joerg Schweizer ${ }^{2}$, Federico Rupi ${ }^{2}$ and Zaneta Stasiskiene ${ }^{1}$
}

\begin{abstract}
Introduction: The accurate analysis and comparison of transport indicators from a large variety of urban areas can help to evaluate the performance of different adopted transport policies. This paper attempts to determine important transport and socio-economic indicators from 151 urban areas and 51 countries, based on comparable, directly observable open-source data such as OpenstreetMap (OSM) and the TomTom database.

Analysis: This is the first, systematic indicator-analysis using recent, open source data from different urban areas around the world. The indicator road kilometers per person, sometimes cited as infrastructure accessibility is calculated by processing OSM data. Information on congestion levels have been taken from the TomTom database and socio-economic data from various, publicly accessible databases. Relations between indicators are identified through correlations and regression models are calibrated, quantifying the relation between transport infrastructure and performance indicators. Three sub-categories of cities with different population sizes (small cities, large cities and metropolises) are defined and studied individually. In addition, a qualitative analysis is performed, putting five different indicators into relation.

Results \& Conclusions: The main results reconfirm previous findings but with a larger sample size and more comparable data. Good correlation values between infrastructure accessibility, socio-economic indicators, and congestion levels are demonstrated. It is shown that cities with higher GDP have generally built more infrastructure which in turn reduces their congestion levels. In particular, for cities with low population density (above approximately 1500 inh. Per sq.km), more roads per inhabitant lead to lower congestion levels; cities with high population density have in general lower congestion levels if the rail infrastructure per person ratio is high. Furthermore, these cities increasing railways per person is more effective in reducing congestions than increasing road length per person.
\end{abstract}

Keywords: Infrastructure accessibility, Congestion, Open source data, OSM, TomTom, Transport policy, Population density

\section{Introduction}

Worldwide, $55 \%$ of the global population lives in urban areas and the present urban population is projected to increase from today's 4 billion people to 6 billion by 2050 [48]. Mainly as a result of migration from rural areas, cities are growing in terms of inhabitants and urban area and form new residential areas outside or further away from the city core. However, the speed of urbanization presents challenges such as meeting the growing demand

\footnotetext{
* Correspondence: ali.dingil@ktu.edu

${ }^{1}$ Institute of Environmental Engineering, Kaunas University of Technology,

Gedimino St. 50, LT-44239 Kaunas, Lithuania

Full list of author information is available at the end of the article
}

for transport infrastructure and affordable housing. Urban zones take different forms and characterizations and urban growth patterns differ amongst regions as a result of socio- economic, cultural, historical and environmental differences. As an example, in the US, people tend to live in low-density, single-family houses and commute by car to work. In Japan by contrast, high-rise residential buildings dominate and workers commute by public transportation (mostly rail-based) [2]. In order to identify the most promising city development policy, it is of primary interest to assess the relations between network infrastructure, socio-economic indicators and the transport system performance based on experiences from existing cities; the 
understanding how cities are shaped by setting the appropriate transport priorities can help to achieve terms of sustainable mobility objectives [36].

The relationship between transport infrastructure expansion and population growth, spatial expansion and land-use change has been highlighted in many works $[1,5,46]$. A tight relationship between transport and urban development has been shown in earlier works [34, 37]. The imbalance between travel demand and transport infrastructure supply as reason for the increase in congestion has been studied by Aljoufie et al. [1]. High congestion levels cause significant costs to society; it has been estimated that exposure to traffic congestion reduces welfare in the US by $\$ 557$ million per year [17] and the estimation of congestion cost to UK economy is approximately $£ 13$ billion per year, in a forecast through 2030 increasing to $£ 21$ billion per year [44]. Congestions impede the proper functioning of more sustainable transport modes such as bus services or cycling; as a consequence, existing bus services could neither meet the growing transport demand, nor meet the demand of the cities' economic development [45]. Due to these negative impacts, congestion levels are a good candidate as transport performance indicator. More specific relations between infrastructure expansion and various transport indicators have been found in the studies cited below.

The expansion of road network generally leads to lower population density in cities: Baum-Snow et al. [4] have shown that the integrated effects of ring roads and highways in Chinese cities gave rise to move $25 \%$ of central inhabitants to surrounding zones. The empirical estimates from Baum-Snow [3] show further that each highway expansion within an urban center of US metropolises causes an average 18\% drop of inhabitants in the city center. An analysis in Wisconsin within 19801990 demonstrated that highway expansions caused population increase in suburban areas and booming the urban sprawl [13]. Similar results have been shown by analyses in California between 1980 and 1994 [12]. At the contrary, rail network expansion has been shown to increase population density at nearby urban rail stations or tracks in several studies, thereby strengthening compactness of urban areas $[6,28,31]$.

The strong correlation between road infrastructure expansion and growth of vehicle ownership has been determined for 50 countries and 35 cities [26]. A positive relationship between highway expansion and car usage has been shown between 1982 and 2009 in the US [32]. A negative correlation between transit ridership and highways length has been found for the Montreal Region [15]. A sharp rise in car ownership in cities with low railway intensity and on the other hand a relatively slow rise of car ownership in cities with high railway intensity have been shown for six Asian megacities located in China, Japan and Thailand [27]. US cities with rail lines experienced larger declines in car usage than cities without rail infrastructure between 2000 and 2009 [25]. Similar modal shifts have been shown to exist in Europe: averaged over 14 LRT systems, approximately $11 \%$ of car drivers have changed to rail [24]. With growing concerns over traffic congestion and pollution from motorized vehicles, Dill and Carr [18] have indicated a positive correlation between bicycle usage and bicycle infrastructure expansion in 43 US cities based on data from Bureau of the Census. This finding has been confirmed and quantified based on a survey from 13 European cities [40].

In summary, an extension of the road network tends to decrease urban population density, decrease the effectiveness of road based public transport -- conditions for favoring an increase in car ownership. A consequence of these effects is a further increase in private road transport demand which is often cited as "induced demand" [30]. Rail and bike networks have been shown to achieve de-congesting effects.

The choice of suitable and relevant indicators for the analysis of transport policies is not obvious. Different definitions of "accessibility" have been used as indicators. Geurs and Van Eck [22] has described various components of "accessibility": land-use, temporal, individual and transport. In an extensive review, Geurs and Wee [23] identified four types of possible accessibility measures: infrastructure-based, location-based, activity-based and utility-based accessibility.

Based on these findings and conditioned by the availability of accessible data, this study will use the length of transport infrastructure per person to quantify the amount of available transport infrastructure. This term is known as infrastructure accessibility [21]. The transport performance is quantified by congestion levels.

The aim of the present study is to shed more light on relations between transport-socio-economic indicators and transport performance indicators. The used data is thought to be comparable across all selected cities, allowing an absolute global evaluation of the transport performance indicator. With respect to previous studies, the number of comparable cities is larger and more recent. Concrete transport policies are addressed by answering this question: under which conditions do more railways and bicycle infrastructure reduce congestion levels?

The next section motivates the data collection for this work and explains the principle data processing steps. The analysis and results are presented and discussed in Analysis and results section, while the conclusions in Sec. 4 summarizes the main findings.

\section{Data collection and processing}

The general approach of this work is to collect, process, correlate and model publicly available and comparable data from a large number of cities around the world. In 
this section, all indicators are defined and the different data sources are described.

\subsection{Socio-economic data-collection of cities}

Socio-economic data has been sampled from a variety of regions around the world -- data from 151 cities which are distributed over 51 countries. Data of at least two consecutive population census as well as administrative spatial area information of urban areas were extracted from City population [16]. Population estimations are used in case local census data have not been available. Recent data of GDP per capita for each urban area have been sourced from the Organization for Economic Co-operation and Development (OECD) database [38]. All GDP values are expressed in American dollars, with an average value of the years 2010-2014. The missing OECD data has been completed from difference sources $[8,14,20,33,41,43]$. The GDP per capita data is available for 139 cities. Population density is calculated as population per spatial area in sq. km. Errors may occur by mixing GDP data from the OECD database with data from other sources. This error type concerns predominantly smaller cities. A general error source is that urban boundary definitions of urban areas are not unified and that GDP data stems from different years. Both issues can lead to compatibility problems with the other data (performance and infrastructure indicators).

\subsection{Performance indicator data}

The central performance indicator used for this study is the congestion level in terms of average daily extra travel time (ADETT), which is the extra travel time in a day with respect to the free-floating traffic scenario, averaged over all monitored traffic participants of a distinct urban area. Comparable data on congestion level are retrievable through the Tomtom database. Tomtom is used by more than 6 million connected GPS devices and traffic is monitored by many million GSM probes and millions of government-owned road sensor [42]. As Tomtom's methodology is sufficiently accurate and unified all over the world, it is a suitable data source for the present study. However, errors may occur for several reasons: the TomTom data is not produced by a representative selection of the population; the special distribution may not be homogeneous; finally the coverage may differ from city to city and may also differ from the urban boundaries found in Socio-economic data-collection of cities section.

\subsection{Infrastructure related indicators from cities}

The infrastructure accessibility (IA) is expressed as infrastructure length per inhabitant (in meter infrastructure per 10 inhabitants). The network infrastructure length is determined for each infrastructure-type of a city from the OSM database, using the OSMNx software package
$[10,11]$. OSM is a crowed sourced, unified and publicly available map of the world. OSM infrastructure data looks trustworthy for many cities, although it still needs some improvements on micro-level details. The OSM data quality seems sufficient for macro-level analyses. OSM consists of three basic components: nodes, ways and relations [39]. Each component has various characterizing attributes, called tags. For instance, the way tags can be used to identify the type of infrastructure.

The Python software package OSMnx extracts and converts OSM network data of the desired location into a directed transport graph (which is a graph object of the Python networkX package) and performs some topological corrections and node clustering simplification. The links of the graph retain the tag information of the ways. Clearly, it is possible to generate sub-graphs for each transport infrastructure (ordinary roads, bikeway and rail). OSMnx does provide options to generate and analyze each of the sub-graphs.

The area of the retrieved transport graph can be specified by providing the polygon surrounding the area or through the name of the city. In the latter case, the administrative boundaries of the desired city is retrieved from OpenStreetMaps' Nominatim database. In most cases, official boundaries have been available on Nominatim and only in rare cases, manual boundaries have been defined. The statistics module of the OSMnx has been used to determine the length of each subgraph, e.g. road length, rail length and bikeway length. Finally the infrastructure accessibility IA is determined for all infrastructure types using the population data (see Sec. 2.1). BRT infrastructure length is sourced from www.brtdata.org [9] and BRT IA is determined in mm per 10 inhabitants. Errors of the infrastructure data are due to the incomplete OSM network or wrongly specified road attributes by volunteer contributors.

\section{Analysis and results}

In this section different analysis are performed and their results are discussed.

\subsection{Correlations within city groups}

In order to render the city comparison more comparable, cities are divided into three sub-groups, according to criteria explained in [19]: cities with a population under 800,000 are defined "small cities" (51 cities), cities with a population between 800,000 and 3 million are defined "mature cities" (56 cities) and cities with a population over 3 million as are defined "metropolis" (44 cities). The distribution of considered cities with respective group-type is shown in the world map on Fig. 1.

The Pearson Correlation Coefficient between different indicators together with the number of samples are shown for different city sizes in Table 1 . The software 


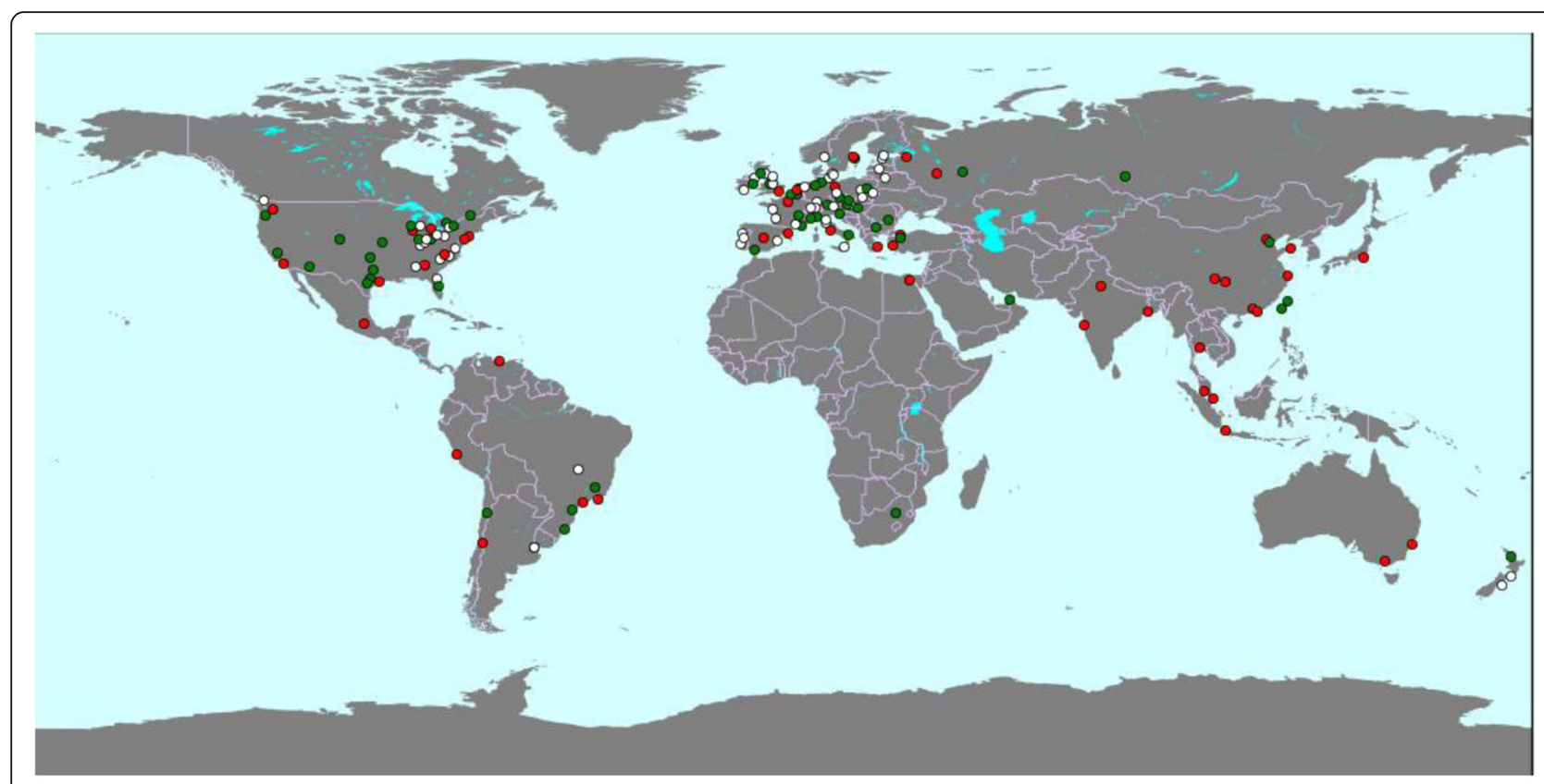

Fig. 1 Distribution of analyzed cities (white = small cities, green = mature cities, red = metropolises)

IBM SPSS 25 is used for the Pearson correlation analyses of variables, while the $95 \%$ confident level is taken into account. Not shown are low correlation whose coefficients have absolute values below 0.2 . Note that the indicator correlations of small cities are often low, probably due to their heterogeneous sizes, land-use and transport networks.

The clearly positive correlation between spatial city area and population growth rate for metropolises, mature cities and all cities is trivial as the number of newborns is proportional to the population size. Also the fact that congestion levels (ADETT) increase with higher population density is not surprising and confirms that cities are struggling keeping transport infrastructure in pace with increasing traffic intensity (trips per sq. $\mathrm{km}$ ). Interesting is the negative relationship between population density and GDP per capita, suggesting that economically weaker cities experience more congestions - this is particularly true for metropolises. The correlation between GDP per capita and road infrastructure accessibility (IA) is strong for metropolises and a little weaker for mature cities. The relationship between GDP per capita and rail IA and between GDP per capita and cycle IA is less pronounced.

The strong relationship between road IA and ADETT is clearly seen for all city sizes. For metropolises, the increase of rail infrastructure shows a similar de- congestionating effect than an increase in road infrastructure, while for small cities rail infrastructure is less correlated with congestions. One hypothesis could be that smaller cities are less congested and there is less pressure to change from car to rail.

Table 1 Pearson correlation coefficient and number of samples ( $N$ ) between different indicators

\begin{tabular}{|c|c|c|c|c|}
\hline Pearson Correlation Coefficient & Metropolises & Mature Cities & Small Cities & All Cities \\
\hline Spatial city area $(\mathrm{Km} \wedge 2)$ and annual population growth & $0,534(N=44)$ & $0,513(\mathrm{~N}=55)$ & - & $0,449(N=150)$ \\
\hline Population density and ADETT & $0,520(N=37)$ & $0,545(\mathrm{~N}=55)$ & - & $0,502(N=143)$ \\
\hline Population density and GDP per capita & $-0,530(N=42)$ & $-0,283(N=56)$ & - & $-0,404(N=139)$ \\
\hline GDP per capita and ADETT & $-0,512(N=36)$ & $-0,304(N=55)$ & - & $-0,332(N=132)$ \\
\hline GDP per capita and road IA & $0,714(\mathrm{~N}=42)$ & $0,571(\mathrm{~N}=56)$ & - & $0,559(\mathrm{~N}=139)$ \\
\hline GDP per capita and rail IA & $0,581(\mathrm{~N}=38)$ & $0,475(\mathrm{~N}=47)$ & - & $0,355(N=124)$ \\
\hline GDP per capita and cycle IA & $0,477(\mathrm{~N}=30)$ & $0,343(N=43)$ & - & - \\
\hline ADETT and road IA & $-0,608(N=37)$ & $-0,750(N=55)$ & $-0,587(\mathrm{~N}=51)$ & $-0,664(N=143)$ \\
\hline ADETT and train IA & $-0,626(N=34)$ & $-0,338(N=46)$ & - & $-0,387(N=127)$ \\
\hline ADETT and cycle IA & $-0,358(\mathrm{~N}=27)$ & $-0,303(N=43)$ & $-0,427(N=42)$ & $-0,337(N=112)$ \\
\hline
\end{tabular}


Table 2 Calibration results of exponential function model Eq.(1) for all cities. $R^{2}=0.515$, sample size $N=147$

\begin{tabular}{llllllll}
\hline Calibration results & Coef & Std Err & $\mathrm{t}$ & $\mathrm{P}>|\mathrm{t}|$ & \multicolumn{2}{l}{ [95.0\% Conf. Int.] } \\
\cline { 7 - 9 } Log(a) & 3.7734 & 0.037 & 100.773 & 0.000 & 3.699 & 3.847 \\
\hline $\mathrm{b}$ & -0.0101 & 0.001 & -12.232 & 0.000 & -0.012 & -0.009 \\
\hline
\end{tabular}

These results confirm the previously mentioned finding that rail infrastructure has a relaxation effect on road traffic for metropolises [7, 29, 47], presumably by shifting car trips to rail trips. Combining the relations between road/rail IA, congestions and GDP per capita, it could be hypothesized that economically strong metropolises can afford to expand road, rail and bicycle infrastructure and are more successful in reducing congestions.

\subsection{Statistical models}

As IA and ADETT are generally well correlated, some statistical models have been calibrated with the entire set of cities as well as on specific subsets. The best fit between road infrastructure accessibility RIA and ADETT of all cities is achieved with an exponential function of the shape:

$$
A D E T T=a \exp (b \text { RIA })
$$

However, the fitting errors with a linear model are only slightly superior. The results of this calibration is shown in Table 2. Despite the high noise levels in the data, the coefficient $b$ is negative, which means decreasing congestions with increasing road IA. This model has been applied for the three city sub-groups and plotted together with the data points in Figs. 2, 3, 4.

A further model is build which includes both, road infrastructure accessibility RIA and train infrastructure accessibility TIA:

$$
A D E T T=c+d R I A+e T I A
$$

As RIA and TIA have the same unit, the coefficients $d$ and $e$ quantify the reduction in traffic-congestions due to an increase/decrease in road infrastructure or train infrastructure, respectively. The interesting question is how the coefficients $d$ and $e$ behave in cities with high and low population densities. Table 3 shows the calibration results of coefficients $d$ and $e$ for cities with a high population density (above 1500 per sq. km) while Table 4 shows the same calibration for cities with low population density (below 1500 per sq. km). The

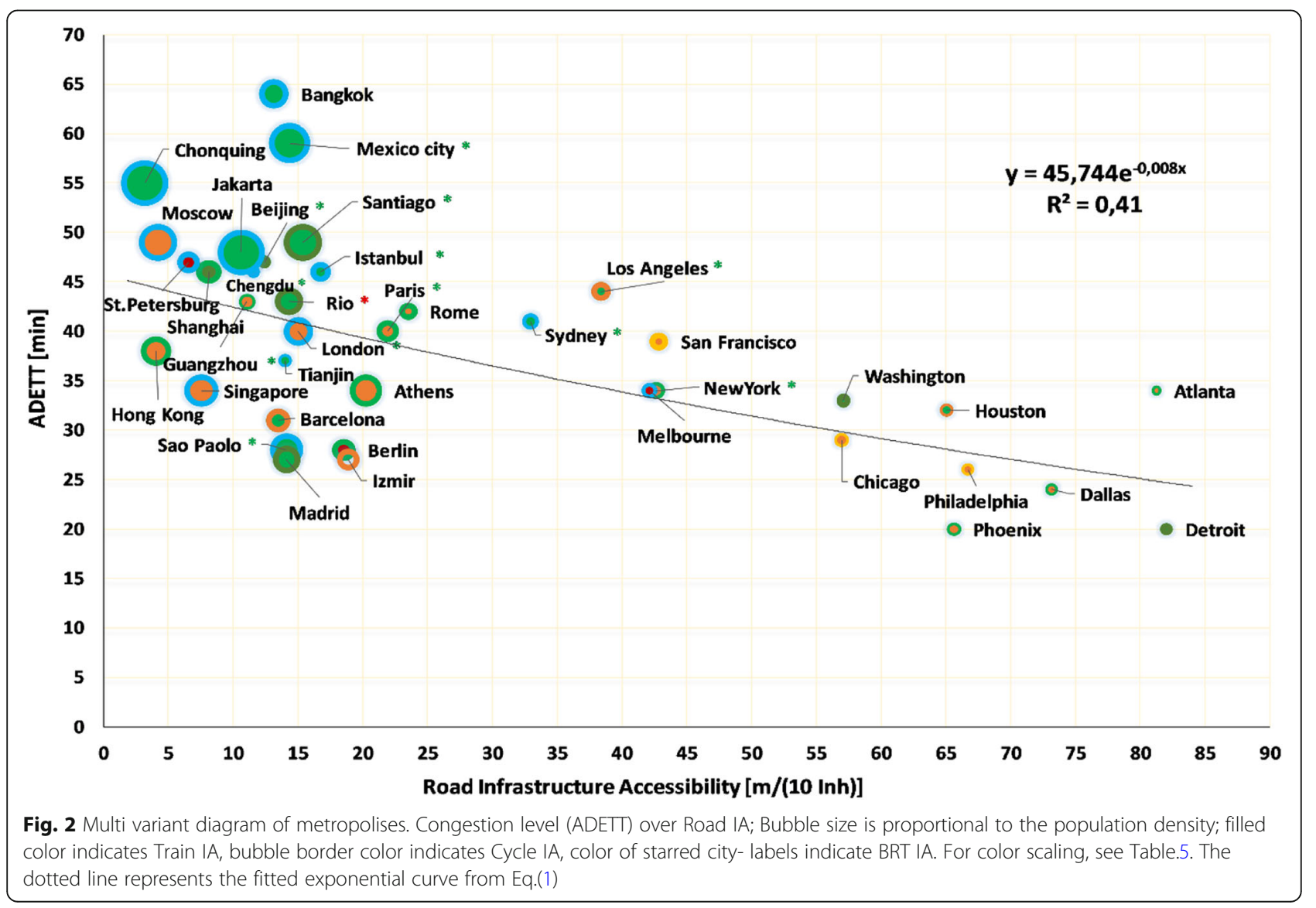




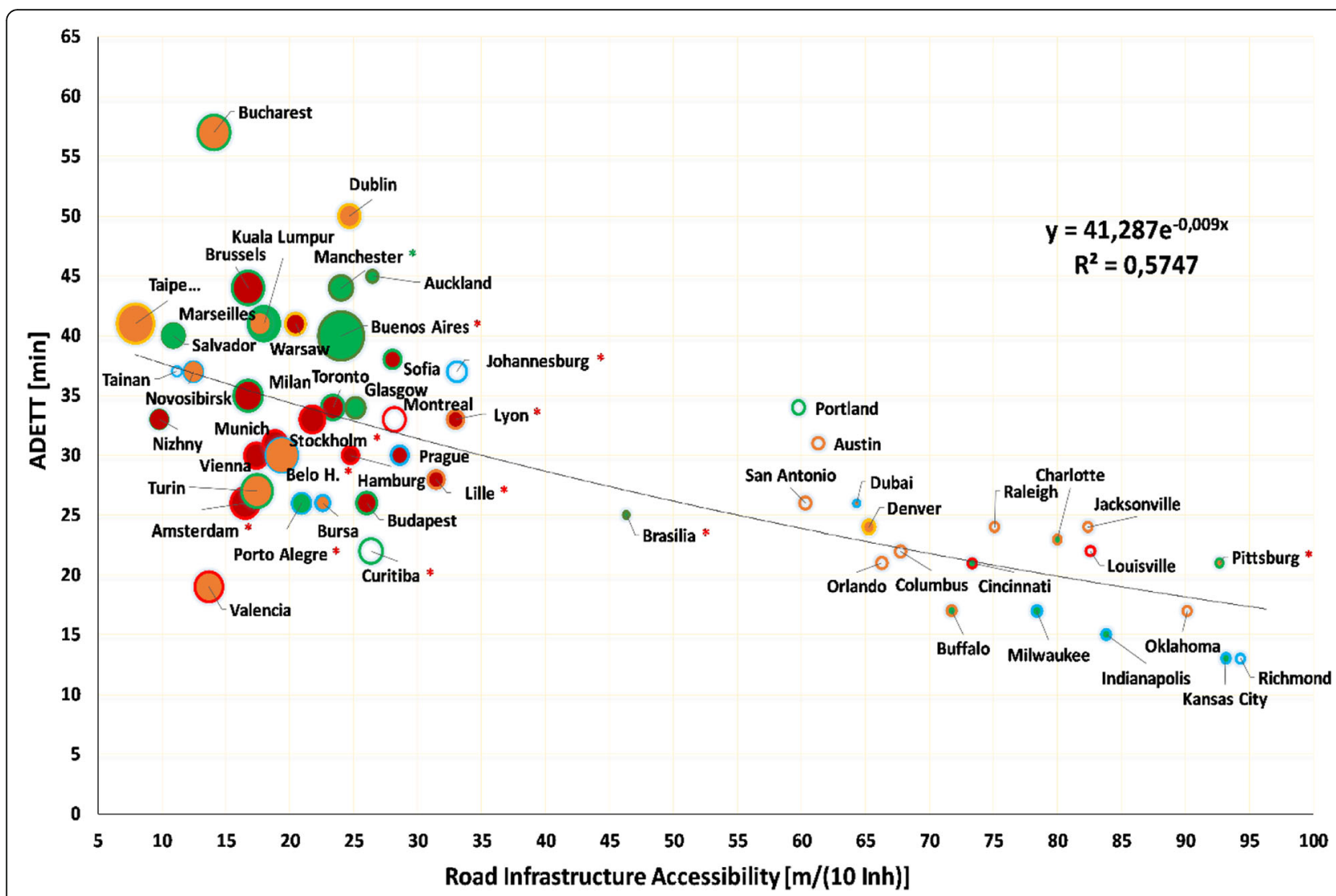

Fig. 3 Multi variant diagram of mature cities. Congestion level (ADETT) over Road IA; Bubble size is proportional to population density; filled color indicates the Train IA, bubble border color indicates Cycle IA, color of starred city- labels indicate BRT IA. For color scaling, see Table.5. The dotted line represents the fitted exponential curve from Eq.(1)

population density division at 1500 per sq. km has been chosen arbitrarily. The main idea has been to isolate extreme space oriented cities in the US and Australia. However, the division at 1500 per sq. km can be varied in reasonable bounds without changing the core message of the results, as detailed below.

The results for high density in Table 3 show that $e$ is significantly more negative than $d$ (four times more negative) and that both coefficients are significant. This result means that an increase in train infrastructure per person reduces more congestion than the increase in road infrastructure per person. One reason why rail lines combat congestion more effectively is probably due to the fact that rail infrastructure has been implemented primarily along the most congested corridors of the city. Therefore, the result of the model does not mean that extending rail network beyond the main traffic corridors will continue to reduce traffic congestion.

The situation for low density cities, shown in Table 4, is less clear: $e$ is only slightly more negative than $d$ and $e$ is statistically not significant (high $P$ value). This means railway building for low density cities appears less effective in reducing congestions with respect to cities with high density cities.

\subsection{Multi-variant comparison}

In an attempt to pursue a holistic approach, the relations between five different indicators are shown in a bubble-type graph where each bubble represents city: the $\mathrm{x}$-axis represents the Road IA and the y-axis represent the ADETT, the fill color indicates Train IA, bubble border color indicates Cycle IA, color of starred city- labels indicate BRT IA. The color scaling is summarized in Table 5 . The bubble graph has been generated for each of the city groups: metropolitan cities in Fig. 2, mature cities in Fig. 3 and small cities on Fig. 4. For each city group, the model from eq. (1) has been calibrated, as the exponential curve showed the best fit. The regression curve and the $R^{2}$ are also indicated in each bubble graph.

The regression analyses for all city groups (Figs. $2-4)$ show $R^{2}$ values between 0.4 and 0.6 , which indicate a good fit, considering the many error sources 


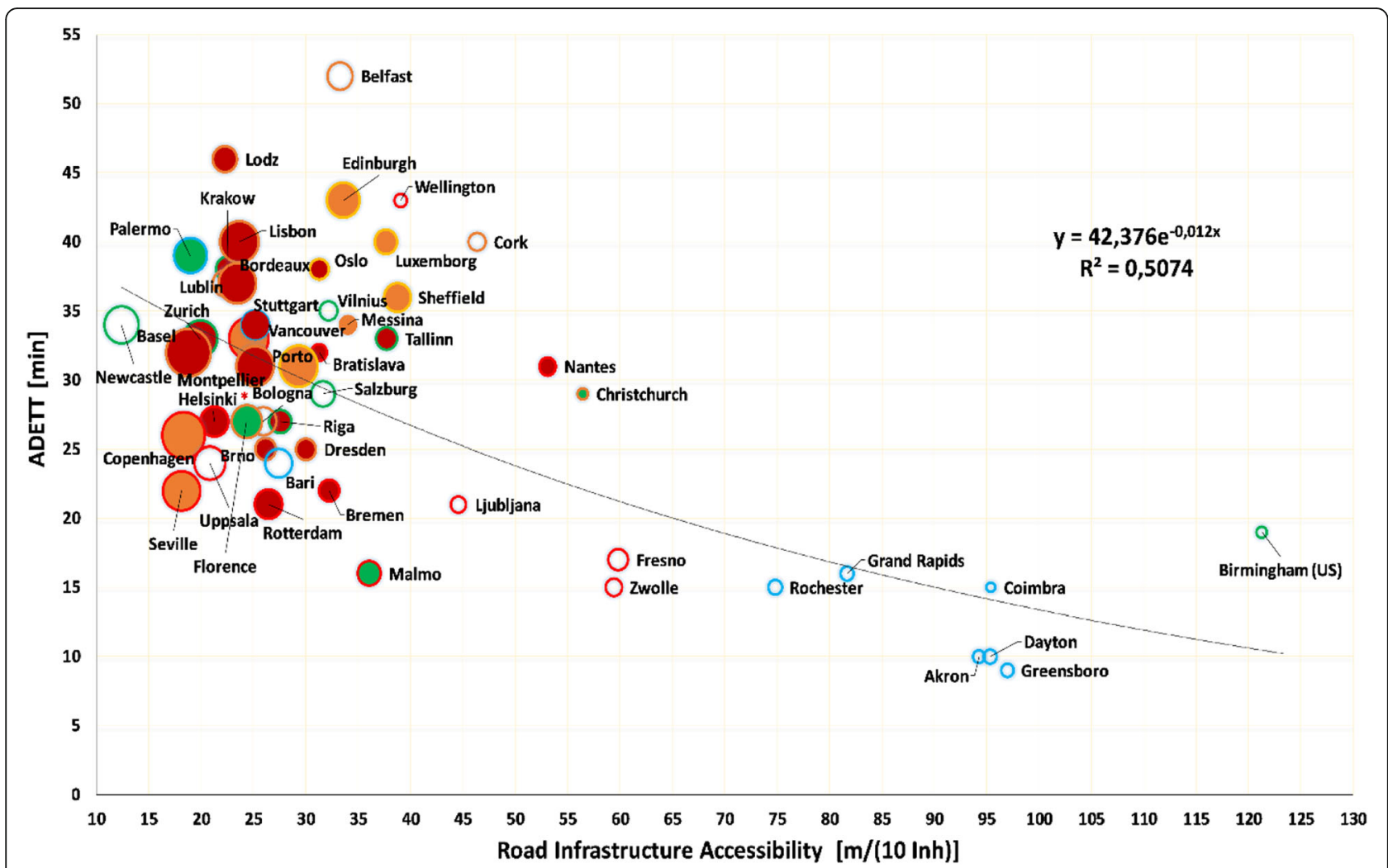

Fig. 4 Multi variant diagram of small cities. Congestion level (ADETT) over Road IA; Bubble size is proportional to the population density; filled color indicates Train IA, bubble border color indicates Cycle IA, color of starred city- labels indicate BRT IA. For color scaling, see Table.5. The dotted line represents the fitted exponential curve from Eq.(1)

mentioned in Data collection and processing section. and the diversity of street-layouts, public transit service characteristics and mobility cultures. In the figures of all three city groups, the cities can be divided in two groups at a Road IA of approximately $35 \mathrm{~m} /(10 \mathrm{Inh})$ : most cities below this threshold have a higher population density, compared with the cities above this threshold. It is evident that many cities with low population densities have built large road networks and have succeeded in reducing congestion. On the other hand, cities with higher population densities appear to have space-constraints and cannot extend their roads network.

Looking closer at cities with higher population densities, it is apparent that those cities with a more

Table 3 Calibration results of linear function model Eq.(2) for cities with population densities above 1500 per sq. $\mathrm{km} . \mathrm{R}^{2}=$ 0.269 , sample size $N=88$

\begin{tabular}{lllllll}
\hline Calibration results & Coef & Std Err & $\mathrm{t}$ & $\mathrm{P}>|\mathrm{t}|$ & \multicolumn{2}{c}{ [95.0\% Conf. Int.] } \\
\hline c & 45.3582 & 2.122 & 21.375 & 0.000 & 41.139 & 49.577 \\
$\mathrm{~d}$ & -0.2386 & 0.083 & -2.880 & 0.005 & -0.403 & -0.074 \\
$\mathrm{e}$ & -0.9706 & 0.246 & -3.950 & 0.000 & -1.459 & -0.482 \\
\hline
\end{tabular}

extensive train network per person (red and orange color) have generally lower congestion levels. This result is consistent with the models in 3.2. However, there are also many exceptions: Dublin and Bucharest have high Train IA but also high congestion levels, while Madrid and Sao Paolo have low Train IA and low congestion levels. Furthermore, the small cities give a less clear picture regarding Train IA and congestions. Some of the small cities with higher population density stand out for their low congestion level most likely due to the presence of a high level of cycling infrastructure; examples are Malmo, Zwolle and Fresno. However, there are not enough example cities with high level of cycling to show a general trend.

Table 4 Calibration results of linear function model Eq.(2) for cities with population densities below 1500 per $/ \mathrm{km}^{\wedge} 2$

$R^{2}=0.638$, sample size $N=39$

\begin{tabular}{lllllll}
\hline Calibration results & Coef & Std Err & $\mathrm{t}$ & $\mathrm{P}>|\mathrm{t}|$ & [95.0\% Conf. Int.] \\
\hline $\mathrm{c}$ & 44.6361 & 2.410 & 18.521 & 0.000 & 39.748 & 49.524 \\
$\mathrm{~d}$ & -0.2602 & 0.036 & -7.166 & 0.000 & -0.334 & -0.187 \\
$\mathrm{e}$ & -0.3835 & 0.282 & -1.358 & 0.183 & -0.956 & 0.189 \\
\hline
\end{tabular}


Table 5 Scaling of multi-variant graphs Figs 2-4

\begin{tabular}{ll}
\hline Urban Train IA & Bubble fill color: \\
{$[\mathrm{km}$ railway per $10 \mathrm{inh}]:$} & red $=$ Train $I \mathrm{~A}>1100$ \\
& orange $=223<$ Train $\mid \mathrm{A}<1100$ \\
& green $=$ Train $I \mathrm{~A}<223$ \\
& non-color $=$ absence of urban rail \\
& Bubble border color: \\
Cycle IA & red $=$ Cycle IA $>1500$ \\
[m cycleway per 10,000 inh]: & orange $=200<$ Cycle IA $<1500$ \\
& green $=10<$ Cycle IA $<200$ \\
& blue $=$ Cycle IA $<10$ \\
BRT IA [m BRT per 10,000 inh]: & Starred Marker $\left(^{*}\right)$ color of city- labels: \\
& red $=$ BRT IA $>150$ \\
& green $=$ BRT IA $<150$ \\
\hline
\end{tabular}

\section{Conclusions}

In the past, the limited availability of comparable data on socio-economics, transport infrastructure and transport performance of cities prevented a holistic analysis with many indicators, due to the lack of variety. These limitations have been overcome by analyzing OSM data, Tomtom data and data from centralized internet databases. To date, no systematic worldwide infrastructure analyses based on OSM data has been performed. Using the Python package called OSMnx, it has been possible to extract different network-types from the OSM data, downloaded from different urban areas of the world. The 151 analyzed cities are distributed over 51 countries. The cities have been analyzed as a whole and within subgroups of cities with distinct population sizes (small cities, mature cities and metropolises). Relationships between socio-economic indicators, infrastructure accessibility and congestion level have been investigated.

Good correlation values between infrastructure accessibility, socio-economic indicators, and congestion levels have been demonstrated with a reasonable goodness of fit. The analyses have shown that cities with higher GDP have built more infrastructure which in turn results in lower congestion levels. The relation between infrastructure accessibility and congestion levels has been quantified using regression models. For cities with low population density (above approximately $1500 \mathrm{Inh}$. per sq. km), more roads per inhabitant lead to lower congestion levels. Metropolises and mature cities with high population density have in general lower congestion levels where rail infrastructure per person is higher. There is significant evidence that, in case of high density cities, an increase in train infrastructure accessibility is more de-congestionating than an increase in road infrastructure accessibility.

The available data could be further exploited to determine the transport-related energy consumption in cities, updating the worldwide comparison of Newman and Kenworthy [35]. However, this would require more information on modal split and trip distances, data which is more difficult to retrieve in a consistent manner.

\section{Author Contributions}

All authors read and approved the final manuscript.

\section{Consent for publication}

Constructive suggestions provided by the reviewers of European

Transportation Research Review are acknowledged.

\section{Competing interests}

The autors declare that they have no competing interest.

\section{Publisher's Note}

Springer Nature remains neutral with regard to jurisdictional claims in published maps and institutional affiliations.

\section{Author details}

${ }^{1}$ Institute of Environmental Engineering, Kaunas University of Technology, Gedimino St. 50, LT-44239 Kaunas, Lithuania. ${ }^{2}$ Civil Engineering Department, University of Bologna, DICAM Viale Risorgimento,2, I-40136 Bologna, Italy.

Received: 9 March 2018 Accepted: 22 November 2018

Published online: 13 December 2018

\section{References}

1. Aljoufie M, Zuidgeest MHP, Brussel MJG, van Maarseveen MFAM (2011) Urban growth and transport understanding the spatial temporal relationship. In: Urban transport XVII : urban transport and the environment in the 21st Century. WIT press, Southampton, pp 315-328

2. Bagan $H$, Yamagata $Y$ (2014) Land-cover change analysis in 50 global cities by using a combination of Landsat data and analysis of grid cells. Environmental Research Letters 9(6):13. 101088/1748-9326/9/6/064015

3. Baum-Snow N (2007) Did highways cause suburbanization? Q J Econ 122(2): 775-805

4. Baum-Snow, N., Brandt, L., Henderson, J. V., Turner, M. A.,Zhang, Q., (2012). Roads, railroads and decentralization of Chinese cities, Citeseer

5. Bertolini $L$ (2012) Integrating mobility and urban development agendas: a manifesto. Disp - The Planning Review 48(1):16-26

6. Beyzatlar MA, Kuştepeli Y (2011) Infrastructure, economic growth and population density in Turkey. International Journal of Economic Sciences and Applied Research 4(3):39-57

7. Bhattacharjee S, Goetz AR (2012a) Impact of light rail on traffic congestion in Denver. J Transp Geogr 22:262-270

8. Brookings Institute, (2018). Global Metro Monitor. Retrieved from: https:// www.brookings.edu/research/global-metro-monitor/

9. Brtdata, (2018). Retrieved from: www.brtdata.org

10. Boeing G (2017) OSMnx: new methods for acquiring, constructing, analyzing, and visualizing complex street networks. Comput Environ Urban Syst 65:126-139

11. Boeing, G., (2018). A Multi-Scale Analysis of 27,000 Urban Street Networks. Environment and Planning B: Urban Analytics and City Science.

12. Cervero, R., (2003). Road expansion, urban growth, and induced travel: a path analysis. J Am Plan Assoc, Vol. 69, No. 2, Spring, pp. 145-163

13. Chi GQ (2010) The impacts of highway expansion on population change: an integrated spatial approach. Rural Sociol 75(1):58-89

14. China Statistical Yearbook, (2016). Retrieved from: http://www.stats.gov.cn/ tjsj/ndsj/2016/indexeh.htm

15. Chakour V, Eluru N (2013) Examining the influence of urban form and land use on bus ridership in Montreal. Procedia -Social and Behavioral Sciences 104:875-884. https://doi.org/10.1016/j.sbspro.2013.11.182

16. City Population, (2018). Retrieved from: www.citypopulation.de 
17. Currie J, Walker R (2011) Traffic congestion and infant health: evidence from e-zpass. Am Econ J Appl Econ 3(1):65-90, 2011

18. Dill J, Carr T (2003) Bicycle commuting and facilities in major U.S. cities: if you build them, commuters will use them. Transp Res Rec 1828:116-123

19. Doxiades KA (1968) Ekistics: an introduction to the science of human settlements. Hutchinson, London

20. Eurostat, (2018). Regional gross domestic product (PPS per inhabitant) by NUTS 2 regions. Retrieved from: http://ec.europa.eu/eurostat/tgm/ refreshTableAction.do?tab=table\&plugin=1\&pcode=tgs00005\&language=en

21. European Environment Agency (2018). Infrastructure density and accessibility by country, https://www.eea.europa.eu/data-and-maps/daviz/ infrastructure-density-and-accessibility-per-country-1

22. Geurs KT, Ritsema van Eck JR (2001) Accessibility measures: review and applications. RIVM report 408505 006, National Institute of Public Health and the Environment, Bilthoven Available at: www.rivm.nl/bibliotheek/ rapporten/408505006.html

23. Geurs KT, van Wee B (2004) Accessibility evaluation of land-use and transport strategies: review and research directions. J Transp Geogr 12(2): 127-140

24. Hass-Klau C, Crampton G, Biereth C, Deutsch V (2004) Bus or light rail: Making the right choice: A financial, operational, and demand comparison of light rail, guided busways and bus lanes. Environmental \& Transport Planning, Brighton and Government of United Kingdom

25. Henry, L. and Litman T., (2014). Evaluating new start transit program performance: comparing rail and bus. Victoria Transport Policy Institute

26. Ingram, G. and Z. Liu, (1999). Determinants of motorization and road provision. In Gomez Ibanez et al. (ed.), Essays in Transportation Economics and Policy, Brookings Institution Press, pp. 325-356

27. Ito K, Nakamura K, Kato H, Hayashi Y (2013) Influence of urban railway development timing on long-term car ownership growth in asian developing mega-cities. J. East. Asia Soc. Transp Stud 10:1076-1085

28. Levinson D (2008) Density and dispersion: the co-development of land use and rail in London. J Econ Geogr 8(1):55-77. https://doi.org/10. 1093/Jeg/Lbm038

29. Litman T (2005) "Impacts of rail transit on the performance of a transportation system" Transportation Research Record 1930. Transportation Research Board 2005:23-29. www.trb.org

30. Litman T (2018) Generated Traffic: Implications for Transport Planning. Report. In: Victoria transport policy institute

31. McMillen DP, Lester TW (2003) Evolving subcenters: employment and population densities in Chicago, 1970-2020. J Hous Econ 12(1):60-81. https://doi.org/10.1016/S1051-1377(03)00005-6

32. Melo P S, Graham D J, Canavan S., (2012). Effects of road investments on economic output and induced travel demand evidence for urbanized areas in the United States, Transp Res Rec, vol. 2297 (pg. 163-171)

33. National Human Development Report for the Russian Federation, (2011) Modernization and Human Development. Retrieved from: http://www.undp. ru/documents/nhdr2011eng.pdf

34. Newman P, Kenworthy JR (1996) The land use-transport connection: An overview. Land Use Policy 13(1):1-22

35. Newman P, Kenworthy J (1988) The transport energy trade-off: fuel-efficient traffic versus fuel-efficient cities. Transportation Research Part A: General 22(3):163-174

36. Newman, P., (2015), "Transport infrastructure and sustainability: a new planning and assessment framework", Vol 4 Issue: 2, pp.140-153, https://doi. org/10.1108/SASBE-05-2015-0009

37. Muller P (2004) Transportation and Urban Form: Stages in the Spatial Evolution of the American Metropolis. The Geography of Urban Transportation, Guilford Publications, pp 59-85

38. OECD, (2018). Regions and cities database. Retrieved from OECD: https:// stats.oecd.org/Index.aspx?DataSetCode=CITIES

39. Openstreetmap (OSM), (2018). Retrieved from: https://wiki.openstreetmap. org/wiki/Tags

40. Schweizer J, Rupi F (2013) Performance evaluation of extreme bicycle scenarios. Procedia - Social and Behavioral Sciences 111:508-517 ISSN 1877-0428

41. Stats NZ (2016) Urban. Development Retrieved from: https://www.stats.govt.nz/

42. Tomtom, (2018). Real time \& historical traffic: TomTom delivers a unique proposition. Retrieved from Tomtom: https://www.tomtom.com/lib/doc/ licensing/RTTHT.EN.pdf

43. Turkish Statistical Institute, (2014). Retrieved from : http://www.turkstat.gov. tr/PreTabloArama.do?metod=search\&araType=vt
44. Urban Transportation Group, (2018). Rail cities UK: our vision for their future. Report Retrieved from: http://www.urbantransportgroup.org/resources/ types/reports/rail-cities-uk-our-vision-their-future

45. Yang Y., Zhang P., Ni S., (2014). Assessment of the Impacts of Urban Rail Transit on Metropolitan Regions Using System Dynamics Model. Transportation research Procedia. T 4 - S. 521-534

46. Wegener M, Fürst F (1999) Land-use transport interaction: State of the art. Project TRANSLAND (integration of transport and land use planning). In: University of Dortmund

47. Winston C, Langer A (2006) The effect of government highway spending on road users' congestion costs. J Urban Econ 60(3):463-483

48. Worldbank, (2018). Urban Development Overview. Retrieved from : http:// www.worldbank.org/en/topic/urbandevelopment/overview

\section{Submit your manuscript to a SpringerOpen ${ }^{\circ}$ journal and benefit from:}

- Convenient online submission

Rigorous peer review

- Open access: articles freely available online

- High visibility within the field

- Retaining the copyright to your article

Submit your next manuscript at $>$ springeropen.com 